\title{
The association between infant feeding pattern and mother's quality of life in Taiwan
}

\author{
Yi-Chun Chen · Wei-Chu Chie - Shu-Chen Kuo • \\ Yu-Hsuan Lin · Shio-Jean Lin · Pau-Chung Chen
}

Received: 19 November 2006/ Accepted: 9 June 2007/Published online: 7 July 2007

(C) Springer Science+Business Media B.V. 2007

\begin{abstract}
Background This study compared the health-related quality of life (HRQOL) of mothers using different infant feeding methods.

Methods We used the Medical Outcomes Study 36-item Short-Form (SF-36) to measure the HRQOL of 1,747 mothers and used the scores to look for associations with infant feeding methods (not breastfeeding, breastfeeding for $<1$ month, breastfeeding 1-5 months, and still breastfeeding at the 6 th month). The mothers were chosen via a
\end{abstract}

Y.-C. Chen

School of Nutrition and Health Sciences, Taipei Medical

University, Taipei, Taiwan

W.-C. Chie

Department of Public Health and Institute of Preventive

Medicine, National Taiwan University College of Public Health,

Taipei, Taiwan

S.-C. Kuo

Department of Healthcare Management, Yuanpei University,

Hsinchu, Taiwan

Y.-H. Lin

Department of Health, Population and Health Research Center,

Bureau of Health Promotion, Taichung, Taiwan

\section{S.-J. Lin}

Department of Pediatrics, National Cheng-Kung University

Hospital, and College of Medicine, National Cheng-Kung

University, Tainan, Taiwan

P.-C. Chen $(\square)$

Institute of Occupational Medicine and Industrial Hygiene,

National Taiwan University College of Public Health,

17 Syujhou Road, Taipei 10055, Taiwan

e-mail: pchen@ntu.edu.tw stratified sampling from the Taiwan national birth registration data between November and December 2003.

Results HRQOL and breastfeeding duration were positively associated. Of the eight unadjusted domain scores of the SF-36, general health perception and mental health were significantly different among these four different infant feeding groups $(P<0.05)$. After controlling for potential confounding factors, mothers who breastfed for 6 months or longer had a higher HRQOL score than the other mothers. In addition, their physical functioning, general health perception and mental health scores were higher than those of mothers who did not breastfeed $(P<0.05)$. Mother's family income and parity and child's health status were also associated with mother's quality of life.

Conclusions Compared to the other mothers, mothers who breastfed for six moths or longer had better HRQOL. However, the limitation that this study was cross-sectional in design should be considered and further studies are needed.

Keywords Breastfeeding - Health-related quality of life · Infant feeding $\cdot$ Mothers $\cdot$ SF-36

$\begin{array}{ll}\text { Abbreviations } \\ \text { BP } & \text { Body pain } \\ \text { GH } & \text { General health perception } \\ \text { HRQOL } & \text { Health-related quality of life } \\ \text { MH } & \text { Mental health } \\ \text { PF } & \text { Physical functioning } \\ \text { RE } & \text { Role limitations due to emotional problems } \\ \text { RP } & \text { Role limitations due to physical health } \\ & \text { problems } \\ \text { SF } & \text { Social functioning } \\ \text { SF-36 } & \text { 36-item Short-Form health survey } \\ \text { VT } & \text { Vitality }\end{array}$




\section{Introduction}

Breastfeeding is a key public health issue. The professional accounts of medicine, nursing, midwifery, public health, and public policy continually emphasize that "breast is best" for infants, the environment, and the global economy. Some also claim that breastfeeding is essential for bonding or securing the relationship between mother and child and that it promotes the health, development, and psychological well-being of the infant [1-6].

Mothers also reap physical health benefits from breastfeeding and lactation [7], such as decreased postpartum bleeding and more rapid uterine involution [8], decreased menstrual blood loss, increased child spacing attributable to lactational amenorrhea [9], earlier return to prepregnancy weight [10], decreased risk of breast cancer [11, 12], decreased risk of ovarian cancer [13], and possibly decreased risk of hip fractures and osteoporosis in the postmenopausal period [14, 15]. For some women, breastfeeding is pleasurable and intimate, but others may experience burden, stress and depression [16, 17]. However, regardless of feeding method, raising an infant can be a stress or loading for the mother's life. We wished to explore if there were differences in the health-related quality of life (HRQOL) among the mothers choosing different infant feeding patterns [18].

To our knowledge, this is the first study primarily comparing the HRQOL of breastfeeding mothers with nonbreastfeeding mothers. We defined HRQOL as the perceived health status and daily functioning associated with changes in health status, and it includes physical and mental health, role limitations, and social functioning. The Medical Outcomes Study 36-item Short-Form (SF-36) measures these health-related constructs [19], and has been used not only in general population [20] but also in comparing parents with different conditions [21-23]. It was widely used and is available in many languages, including a psychometrically validated Taiwanese version [24, 25]. In this study, we compared the HRQOL of mothers using different infant feeding methods in Taiwan.

\section{Methods}

\section{Study population}

The Taiwan Birth Cohort Pilot Study (TBCS) is a prospective longitudinal cohort study. In the current study, we used a multistage stratified systematic sampling design to obtain representative samples from the Taiwan national birth registration data between November and December 2003. We ranked a total of 369 towns in Taiwan into 12 strata according to the administrative division (4 strata) and the total fertility rate ( 3 strata). Using the principle of proportion probability to size we randomly sampled 29 towns in Taiwan. Women and newborns, a total of 2,048 pairs, from 29 towns were recruited [26, 27]. All study participants provided informed consent as approved by the Ethics Review Board of the National Taiwan College of Public Health.

\section{Data collection}

We used data from the first pilot survey of TBCS. We first extracted the parents' and infants' basic demographic information from the Taiwan national birth registration data. We then conducted a home interview with 1,783 (87\% of the original 2,048) postpartum women in the 6th month after their deliveries by using a structured questionnaire and the Taiwanese version of the SF-36 in the period from April to June 2004. Thirteen percent of the original pool did not participate for various reasons. Ultimately, 36 interviews were excluded because of incomplete questionnaires $(N=21)$ or because mothers were handicapped or ill $(N=15)$, leaving a sample size of 1,747 .

\section{Health-related Quality of Life measures}

The Medical Outcome Study 36-item Short-Form health survey (SF-36) is a generic health-related quality of life questionnaire. The Taiwanese version was translated, back translated, and judged for similar meaning, and it demonstrated good reliability and validity in a healthy adult sample $[24,25]$. It is identical to the original Version 1 of SF-36 and contains 36 items, grouped into the following eight domains: physical functioning ( $\mathrm{PF}, 10$ items), rolephysical functioning (RP, 4 items), body pain (BP, 2 items), general health perception (GH, 5 items), vitality (VT, 4 items), social functioning (SF, 2 items), role-emotional functioning (RE, 3 items), and mental health (MH, 5 items). The score on each scale ranges from 0 to 100 , with a higher score indicating better health or functioning.

Infant feeding methods

Data including infant feeding methods and potential confounding variables were obtained from the Taiwan national birth registration and the interview questionnaire. Infant feeding methods were stratified into four groups: never breastfeeding, breastfeeding $<1$ month, 1-5 months, and $\geq 6$ months. Never breastfeeding means bottle feeding; breastfeeding less than 1 month means trying to breastfeeding but failed; breastfeeding between 1 and 5 months means continued breastfeeding for at least 1 month but less than 6 months; and breastfeeding at the 6th month means still breastfeeding. 
Potential confounding variables

We used the categorization of potential confounding variables according to previous studies in Taiwan [26, 27]. Mothers were grouped into younger or older than 30 years. Their educational levels were stratified into three groups: university and college or above, senior high school, and below senior high school. Information on maternal occupation was collected including 1 year before the current pregnancy, and during the pregnancy and postpartum periods. Maternal current employment status was defined either as mothers returning to work after maternity leave, or they did not work during pregnancy but worked after delivery and was later summarized into two groups: employed and unemployed. Family annual income was defined as the total parental income per year, and it was divided into four categories in new Taiwan dollars (NT\$ = new Taiwan dollars, US\$ $1=$ NT\$ 32 in 2005): 390,000 or lower, 400,000590,000, 600,000-990,000, and 1,000,000 or higher. Parity was grouped into 0,1 and 2. Variables related to infants included gender and health status. Infants who did not have emergency treatment or hospitalization since birth were considered to be in good health. Nursery type included parameters such as the mother being the major caregiver and the mother sleeping with the baby at night.

\section{Statistical analysis}

A chi-square test was performed to examine the differences in basic characteristics and potential related factors within the four infant feeding groups. Analysis of variance (ANOVA) and a post hoc Scheffe test were used to examine the scores of the SF-36 among the four infant feeding groups. To control for mother's age, education, employment, family income, and parity, infant's gender and health status, and mother-infant sleep pattern, the differences of SF-36 scores among the groups were evaluated by analysis of covariance (ANCOVA) and a least significant difference (LSD) multiple comparisons test. We also used multivariate linear regression analysis to explore the contribution of other potential related factors on mothers' quality of life. If two or more variables were highly correlated, separate models were presented for each of the collinear variables to avoid collinearity. The statistical threshold for significance was set at 0.05 . Statistical analyses were conducted with SPSS for Windows, Release 12.0.

\section{Results}

Socio-demographic characteristics

The characteristics of the subjects are summarized in Table 1. Mother's mean age was $27.0 \pm 4.9$ years. Almost half of the women had either a high school education $(42.5 \%)$ or a university education $(48.4 \%)$ and $56.8 \%$ were working mothers. Among the families, $34.3 \%$ had an annual income of NT\$ 600,000-990,000. Among mothers, $51.1 \%$ were first-time mothers, $55.2 \%$ of children were male, and $69.1 \%$ of children's health statuses were good. Among all mothers, $71.2 \%$ took care of their babies and $80.3 \%$ slept with their babies. Mothers who breastfed longer than 6 months were older $(40.4 \% \geq 30$ years $)$, unemployed $(64.0 \%)$, more likely to take care of their baby $(86.2 \%)$, and almost all slept with their baby (96.3\%).

\section{Comparisons of quality of life among different groups}

Table 2 shows the SF-36 scores of different groups of mothers divided by infant feeding method. There was a positive association between quality of life and breastfeeding duration. In most of the eight domains, mothers who breastfed for $\geq 6$ months reported higher scores than mothers in the other three groups. The differences among these four groups were statically significant for physical functioning $(P=0.046)$, general health perception $(P<0.001)$, and mental health $(P=0.026)$. The differences between mothers who did not breastfeed at all and mothers who breastfed for $\geq 6$ months were statically significant for physical functioning and general health perception $(P<0.05)$. The differences between mothers who breastfed for $<1$ month and mothers who breastfed for $\geq 6$ months were statically significant for general health perception and mental health $(P<0.05)$.

Effect of infant feeding method on mother's quality of life

Table 3 summarizes the adjusted SF-36 scores of the four different groups of mothers. The comparison was adjusted for mother's age, education, employment, family income, and parity, infant's gender and health status, and motherinfant sleep pattern. After adjusting for these factors, mothers who breastfed for $\geq 6$ months still had higher scores than mothers in the other groups. The differences among these four groups were statically significant for general health perception $(P<0.001)$ and mental health $(P=0.026)$. Compared to mothers who did not breastfeed at all and mothers who breastfed for $<1$ month, mothers who breastfed for $\geq 6$ months had statistically significant higher scores for general health perception and mental health $(P<0.05)$.

Determinants of quality of life for all mothers

Table 4 shows the results of the regression analysis. Except for infant feeding method, mother's education, family income, and parity, and child's health status were associated with mothers' quality of life. Higher education level and a 
Table 1 Characteristics of study subjects

\begin{tabular}{|c|c|c|c|c|c|c|}
\hline Characteristics & $\begin{array}{l}\text { Total } \\
N(\%)\end{array}$ & $\begin{array}{l}\text { Never } \\
N(\%)\end{array}$ & $\begin{array}{l}<1 \text { month } \\
N(\%)\end{array}$ & $\begin{array}{l}1-5 \text { months } \\
N(\%)\end{array}$ & $\begin{array}{l}\geq 6 \text { months } \\
N(\%)\end{array}$ & $P$-value \\
\hline Total number & $1747(100)$ & $286(100)$ & $732(100)$ & $432(100)$ & $297(100)$ & \\
\hline \multicolumn{7}{|l|}{ Mother's factor } \\
\hline \multicolumn{7}{|l|}{ Age (years) } \\
\hline$\geq 30$ & $552(31.6)$ & $85(29.7)$ & $202(27.6)$ & $145(33.6)$ & $120(40.4)$ & 0.001 \\
\hline$<30$ & $1195(68.4)$ & $201(70.3)$ & $530(72.4)$ & $287(66.4)$ & $177(59.6)$ & \\
\hline Mean \pm SD & $27.0 \pm 4.9$ & $26.6 \pm 5.3$ & $26.5 \pm 4.8$ & $27.4 \pm 4.4$ & $28.2 \pm 5.3$ & $<0.001$ \\
\hline \multicolumn{7}{|l|}{ Education } \\
\hline$\geq$ University & $714(40.9)$ & $59(20.6)$ & $293(40.0)$ & $223(51.6)$ & $139(46.8)$ & $<0.001$ \\
\hline High school & $740(42.4)$ & $150(52.4)$ & $335(45.8)$ & $160(37.0)$ & $95(32.0)$ & \\
\hline$<$ High school & $293(16.8)$ & $77(26.9)$ & $104(14.2)$ & $49(11.3)$ & $63(21.1)$ & \\
\hline \multicolumn{7}{|c|}{ Current employment status } \\
\hline Yes & $993(56.8)$ & $157(54.9)$ & $448(61.2)$ & $281(65.0)$ & $107(36.0)$ & $<0.001$ \\
\hline No & $754(43.2)$ & $129(45.1)$ & $284(38.8)$ & $151(35.0)$ & $190(64.0)$ & \\
\hline \multicolumn{7}{|c|}{ Family income per year (NT\$) } \\
\hline$\geq 1,000,000$ & $414(23.7)$ & $162(22.1)$ & $162(22.1)$ & $134(31.0)$ & $81(27.3)$ & $<0.001$ \\
\hline $600,000-990,000$ & $599(34.3)$ & $108(37.8)$ & $255(34.8)$ & $155(35.9)$ & $81(27.3)$ & \\
\hline $400,000-590,000$ & $370(21.2)$ & $64(22.4)$ & 158 (21.6) & $78(18.1)$ & $70(23.6)$ & \\
\hline$\leq 390,000$ & $364(20.8)$ & 77 (26.9) & $157(21.4)$ & $65(15.0)$ & 65 (21.9) & \\
\hline \multicolumn{7}{|l|}{ Parity } \\
\hline$\geq 2$ & $197(11.3)$ & $44(15.4)$ & $75(10.2)$ & $40(9.3)$ & $38(12.8)$ & 0.021 \\
\hline 1 & $654(37.4)$ & $118(41.3)$ & $281(38.4)$ & $151(35.0)$ & $104(35.0)$ & \\
\hline 0 & $896(51.3)$ & $124(43.4)$ & $376(51.4)$ & $241(55.8)$ & $155(52.2)$ & \\
\hline \multicolumn{7}{|l|}{ Infant factor } \\
\hline \multicolumn{7}{|l|}{ Gender } \\
\hline Male & $965(55.2)$ & $153(53.5)$ & $427(58.3)$ & $228(52.8)$ & $157(52.9)$ & 0.178 \\
\hline Female & $782(44.8)$ & $133(46.5)$ & $305(41.7)$ & $204(47.2)$ & $140(47.1)$ & \\
\hline \multicolumn{7}{|l|}{ Health status } \\
\hline Good & $540(30.9)$ & $84(29.4)$ & $232(31.7)$ & $132(30.6)$ & $92(31.0)$ & 0.907 \\
\hline Not good & $1207(69.1)$ & $202(70.6)$ & $500(68.3)$ & $300(69.4)$ & $205(69.0)$ & \\
\hline \multicolumn{7}{|l|}{ Mother's nursery } \\
\hline \multicolumn{7}{|l|}{ Major care giver } \\
\hline Yes & $1244(71.2)$ & $220(76.9)$ & 473 (64.6) & $295(68.3)$ & $256(86.2)$ & $<0.001$ \\
\hline No & $503(28.8)$ & $66(23.1)$ & $259(35.4)$ & 137 (31.7) & $41(13.8)$ & \\
\hline \multicolumn{7}{|l|}{ Sleep with baby } \\
\hline Yes & $1403(80.3)$ & $224(78.3)$ & $545(74.5)$ & $348(80.6)$ & $286(96.3)$ & $<0.001$ \\
\hline No & $344(19.7)$ & $62(21.7)$ & $187(25.5)$ & $84(19.4)$ & $11(3.7)$ & \\
\hline
\end{tabular}

greater number of children were negatively related to mothers' general health perception and mental health. A higher family income, child's good health status, and breastfeeding for $\geq 6$ months were positively related to mother's general health perception and mental health.

\section{Discussion}

To promote infants' and children's health, the World Health Organization recommends that infants should be exclusively breastfed for the first 6 months of their life and that they should continue to receive breast milk for the remainder of their first and second years [28]. The importance of breastfeeding is generally accepted, but its effect on the quality of life of breastfeeding mothers had not been fully evaluated until now. Herein, we report the existence of a positive correlation between a mother's quality of life and breastfeeding. Mothers who breastfed for 6 months or longer reported a significantly higher quality of life than those who breastfed for less than 6 months or never breast at all. In particular, mothers who breastfed for 6 months or longer scored higher than non-breastfeeding mothers in 
Table 2 SF-36 scores of different infant feeding groups

\begin{tabular}{llllr}
\hline SF-36 Domains & $\begin{array}{l}\text { Never } \\
\text { Mean } \pm \text { SD }\end{array}$ & $\begin{array}{l}<1 \text { month } \\
\text { Mean } \pm \text { SD }\end{array}$ & $\begin{array}{l}1-5 \text { months } \\
\text { Mean } \pm \text { SD }\end{array}$ & $\begin{array}{l}\geq 6 \text { months } \\
\text { Mean } \pm \text { SD }\end{array}$ \\
\hline PF & $90.03 \pm 14.72^{\mathrm{a}}$ & $91.99 \pm 11.58^{\mathrm{ab}}$ & $91.66 \pm 12.29^{\mathrm{ab}}$ & $92.83 \pm 12.10^{\mathrm{b}}$ \\
RP & $82.69 \pm 30.53$ & $83.67 \pm 29.76$ & $81.71 \pm 31.61$ & $85.86 \pm 28.66$ \\
BP & $86.29 \pm 18.54$ & $84.06 \pm 17.53$ & $85.83 \pm 17.18$ & $85.37 \pm 16.67$ \\
GH & $70.20 \pm 19.86^{\mathrm{a}}$ & $70.46 \pm 18.89^{\mathrm{a}}$ & $73.84 \pm 17.69^{\mathrm{ab}}$ & $75.89 \pm 16.41^{\mathrm{b}}$ \\
VT & $61.96 \pm 18.53$ & $60.63 \pm 17.76$ & $61.06 \pm 16.87$ & 6.316 \\
SF & $82.95 \pm 17.84$ & $82.92 \pm 15.40$ & $82.90 \pm 16.25$ & $83.84 \pm 18.48$ \\
RE & $73.43 \pm 37.79$ & $74.91 \pm 35.95$ & $76.00 \pm 34.70$ & $77.67 \pm 35.71$ \\
MH & $66.28 \pm 16.35^{\mathrm{a}}$ & $65.73 \pm 15.84^{\mathrm{a}}$ & $66.98 \pm 15.59^{\mathrm{ab}}$ & $69.31 \pm 15.30^{\mathrm{b}}$
\end{tabular}

Scores with superscripts indicate the findings according to the post hoc Scheffe test. Scores with different superscripts differ significantly from each other in that row. Scores with no superscripts do not differ significantly from any other score in that row

Table 3 Adjusted SF-36 scores of different infant feeding groups ${ }^{e}$

\begin{tabular}{|c|c|c|c|c|c|}
\hline SF-36 Domains & $\begin{array}{l}\text { Never }^{\mathrm{a}} \\
\text { Mean (SE) }\end{array}$ & $\begin{array}{l}<1 \text { month }^{\mathrm{b}} \\
\text { Mean }(\mathrm{SE})\end{array}$ & $\begin{array}{l}1-5 \text { months } \\
\text { Mean }(\mathrm{SE})\end{array}$ & $\begin{array}{l}\geq 6 \text { months }{ }^{\mathrm{d}} \\
\text { Mean (SE) }\end{array}$ & $P$-value \\
\hline$P F^{f}$ & $90.18(0.75)$ & $91.92(0.46)$ & $91.59(0.60)$ & $92.94(0.74)$ & 0.066 \\
\hline $\mathrm{RP}$ & $82.54(1.82)$ & $83.60(1.13)$ & 81.54 (1.47) & $86.44(1.80)$ & 0.192 \\
\hline BP & $85.85(1.05)$ & $83.92(0.65)$ & $86.12(0.85)$ & $85.72(1.04)$ & 0.134 \\
\hline $\mathrm{GH}^{\mathrm{g}}$ & $70.13(1.10)$ & $70.60(0.68)$ & $73.87(0.89)$ & $75.58(1.09)$ & $<0.001$ \\
\hline VT & 61.09 (1.06) & $60.71(0.66)$ & $61.61(0.85)$ & $63.27(1.05)$ & 0.235 \\
\hline SF & $82.58(0.97)$ & $83.00(0.60)$ & $83.04(0.78)$ & $83.82(0.96)$ & 0.833 \\
\hline $\mathrm{RE}$ & $72.86(2.16)$ & $74.78(1.34)$ & 76.02 (1.74) & $78.51(2.15)$ & 0.292 \\
\hline $\mathrm{MH}^{\mathrm{h}}$ & $66.05(0.95)$ & $65.85(0.59)$ & $67.04(0.76)$ & $69.14(0.94)$ & 0.026 \\
\hline
\end{tabular}

e Values were adjusted for mother's age, education, employment, family income, and parity, infant's gender and health status, and motherinfant sleep pattern

f $\mathrm{a}<\mathrm{b} ; \mathrm{a}<\mathrm{d}$

g $\mathrm{a}<\mathrm{c} ; \mathrm{a}<\mathrm{d} ; \mathrm{b}<\mathrm{c} ; \mathrm{b}<\mathrm{d}$

h $\mathrm{a}<\mathrm{d} ; \mathrm{b}<\mathrm{d}$

terms of physical functioning, general health, and mental health.

Breastfeeding is an essential component in the confirmation of motherhood [29]. Our findings indicate that breastfeeding helps enhance a mother's quality of life, with duration of breastfeeding being a key factor. These findings agree with some studies [30-34] and conflict with others $[16,17,35,36]$ that examined the consequences of breastfeeding in areas other than quality of life. Mezzacappa et al. found that breastfeeding was associated with fewer gastrointestinal and upper respiratory symptoms and fewer doctor visits [32, 37], and Kavanaugh et al. reported that mothers of preterm infants perceived specific emotional advantages from their breastfeeding experiences [30]. Several studies have also reported that breastfeeding was associated with decreased stress, depression, and negative moods [32-34, 37].

On the other hand, breastfeeding is not a positive experience for some women. Schmied and Lupton reported that for some, breastfeeding was pleasurable and intimate, a vital means of emotional connection to their infants, but that for others it was difficult, unpleasant, and disruptive [17]. Schmied and Barclay found that the continual demands from a breastfeeding infant were physically and emotionally exhausting for some women [16]. Mozingo et al. reported that women spoke poignantly about a sense of failure, guilt, or shame and had lingering self-doubts about discontinuing breastfeeding [35]. Harris et al. noted that some women's breastfeeding experiences did not fit their perfect post-birth images, making them feel unable to control their life and damaging their self-esteem [36]. Thus, for some women the breastfeeding experience is not smooth and comfortable, so not every woman enjoys the benefits.

In this cross-sectional study, it is possible that mothers who experienced breastfeeding difficulties reported a poorer quality of life and discontinued breastfeeding early, whereas those who survived such problems continued 
Table 4 Regression model to predict quality of life in mothers
* $P<0.05 ; * * \quad P<0.01$ *** $P<0.001$

\begin{tabular}{|c|c|c|}
\hline Characteristics & $\mathrm{GH}$ & MH \\
\hline Intercept & $69.64 * * *$ & $66.86^{* * *}$ \\
\hline \multicolumn{3}{|l|}{ Mother's factor } \\
\hline \multicolumn{3}{|l|}{ Age (years) } \\
\hline$\geq 30$ vs. $<30$ & -0.44 & 0.81 \\
\hline \multicolumn{3}{|l|}{ Education } \\
\hline$\geq$ University vs. $<$ high school & $-3.71 *$ & $-4.54 * * *$ \\
\hline High school vs. $<$ high school & -2.41 & $-2.70^{*}$ \\
\hline \multicolumn{3}{|l|}{ Current employment status } \\
\hline Yes vs. no & -1.55 & -1.16 \\
\hline \multicolumn{3}{|l|}{ Family income per year (NT\$) } \\
\hline$\geq 1,000,000$ vs. $\leq 390,000$ & $3.49 *$ & $4.23 * *$ \\
\hline $600,000-990,000$ vs. $\leq 390,000$ & $3.48 * *$ & 1.90 \\
\hline $400,000-590,000$ vs. $\leq 390,000$ & 2.16 & 1.19 \\
\hline \multicolumn{3}{|l|}{ Parity } \\
\hline 1 vs. 0 & -1.29 & -0.88 \\
\hline$\geq 2$ vs. 0 & $-4.46^{* *}$ & $-2.78 *$ \\
\hline \multicolumn{3}{|l|}{ Infant factor } \\
\hline \multicolumn{3}{|l|}{ Gender } \\
\hline Male vs. female & 0.47 & 0.56 \\
\hline \multicolumn{3}{|l|}{ Health status } \\
\hline Good vs. not good & $2.69 * *$ & $2.22 * *$ \\
\hline \multicolumn{3}{|l|}{ Mother's nursery } \\
\hline \multicolumn{3}{|l|}{ Sleep with baby } \\
\hline Yes vs. no & 0.50 & -0.57 \\
\hline \multicolumn{3}{|l|}{ Breastfeeding duration } \\
\hline$\geq 6$ months vs. never & $5.53 * * *$ & $2.95 *$ \\
\hline $1-5$ months vs. never & $3.79 * *$ & 0.92 \\
\hline$<1$ month vs. never & 0.50 & -0.25 \\
\hline
\end{tabular}

breastfeeding for 6 months or more. One study in Barbados reported an association between depressive symptoms at 7 weeks postpartum and reduced breastfeeding preference at that time and thereafter [38]. Two other studies also have shown that early breastfeeding problems and a lack of support were responsible for the early cessation of breastfeeding [39, 40]. According to several quality of life surveys about parents with sick children, a lower quality of life may be the result of a more stressful family and social situation [22, 41, 42]. Heinig noted that a mother who is poor, ill, exploited, or abused is denied the ability to choose a healthy behavior and indeed, in many instances, will not breastfeed or only exclusively breastfeed for a very short time [43].

Furthermore, mothers who are able to breastfeed longer might also have better social support and therefore report a higher quality of life. In addition to infant feeding methods, a maternal family income and parity, and child's health status were also associated with a mother's quality of life. More children, an unhealthy child, and lower income suggest a more stressful motherhood and a lower quality of life. Previous studies demonstrated that lower social support, childcare stress and life stress are associated with worse mother's quality of life [44-46]. It is possible, then, that breastfeeding mothers reported less stress than bottle feeding mothers not only because of lactation effects, but also because they had greater resources to cope. Flacking et al. noted the importance of the quality of social bonds for experiencing satisfying breastfeeding and becoming a mother [47], and Isabella reported that long-term breastfeeding mothers were most likely to characterize their marriages as satisfying and loving and were most satisfied with the nature and extent of the support they received from their husbands [48]. Galtry concluded that to achieve a high rate of breastfeeding, both socio-cultural support and labor/market/health/early childhood policies are very important [49]. Paying close attention to the aforementioned issues may help promote the continuation of breastfeeding among mothers who have already started.

The sense of empowerment associated with successful breastfeeding has been documented. Heinig opined that breastfeeding cannot be viewed in isolation as a means to 
promote maternal and child health, especially in a world in which disparities in access and quality of care continue to exist [43]. Efforts to support breastfeeding should be implemented alongside programs designed to improve maternal and child health in a broader context. Policies to enhance scheduling flexibility and privacy for breastfeeding mothers may also be important.

There is an interesting finding in relation to $\mathrm{MH}$ scores in the group of mothers who breastfed for less than 1 month, as these were found to have the lowest MH score, even more so than those who never breastfed. This result supports previous suggestions that a failed attempt results in decreased mother's mental health even more so than no attempt or successful breastfeeding [50]. We also found that mothers who still breastfeed at the 6th month were much more likely to sleep with their babies. (Table 1) Previous studies show that bed-sharing may promote breastfeeding [51, 52]. Although a higher proportion of Taiwanese mothers were more likely to sleep with their babies, there are cultural differences in infant rearing practice particularly in relation to co-sleeping.

However, we did not explore all the dimensions potentially related to mother's quality of life including mother's social network and self-esteem, the quality of mother's love and care for the baby, the quality of mother's relation to partner and sexual life, and even the infant's quality of life. Taiwan is a traditional Chinese culture in which the measurement of sensitive issues such as sexual life is difficult. Although we attempted to collect this information, we are concerned that the quality may be poor in the large cohort study. In addition, we did not collect the information on previous breastfeeding experience. It may influence the initiation and continuation of breastfeeding in multiparous mothers. If included this variable into the models, there could be overadjustment of estimates.

\section{Conclusions}

Mothers who breastfed for 6 months or longer reported a better quality of life compared to other mothers in terms of general health and mental health. These results may encourage mothers to breastfeed their infants which can improve the lives of not only children but also mothers themselves. However, the limitation that this study was cross-sectional in design should be considered and further studies are needed to better understand the mechanisms involved in this relationship between breastfeeding and mother's quality of life.

Acknowledgements This study was based on the data from Taiwan Birth Cohort Study Pilot Database and supported by the grants (BHPPHRC-92-4 and DOH93-HP-1702) from the Bureau of Health Promotion, Department of Health, Taiwan. We thank the enduring support and assistance from Professor Tung-Liang Chiang, Institute of Health Policy and Management, National Taiwan University College of Public Health, Taipei, Taiwan; Professor Meng-Chin Lee, Institute of Medicine, Professor Hui-Sheng Lin, School of Public Health, Chung Shan Medical University. Taichung, Taiwan; and Professor Bih-Ching Shu, Institutes of Allied Health Sciences, College of Medicine, National Cheng Kung University, Tainan, Taiwan.

\section{References}

1. Gartner, L. M., Morton, J., \& Lawrence, R. A. et al. (2005). Breastfeeding and the use of human milk. Pediatrics, 115, 496-506.

2. Reynolds, A. (2001) Breastfeeding and brain development. Pediatrics Clinics of North America, 48, 159-171.

3. Blaymore Bier, J. A., Oliver, T., \& Ferguson, A. et al. (2002). Human milk reduces outpatient upper respiratory symptoms in premature infants during their first year of life. Journal of Perinatology, 22, 354-359.

4. Rao, M. R., Hediger, M. L., \& Levine, R. J. et al. (2002). Effect of breastfeeding on cognitive development of infants born small for gestational age. Acta Paediatrica, 91, 267-274.

5. Feldman, R., \& Eidelman, A. I. (2003). Direct and indirect effects of breast milk on the neurobehavioral and cognitive development of premature infants. Developmental Psychology, 43, 109-119.

6. Kramer, M. S., Guo, T., \& Platt, R. W. et al. (2003). Infant growth and health outcomes associated with 3 compared with 6 mo of exclusive breastfeeding. American Journal of Clinical Nutrition, 78, 291-295.

7. Labbok, M. H. (2001). Effects of breastfeeding on the mother. Pediatrics Clinics of North America, 48, 143-158.

8. Chua, S., Arulkumaran, S., \& Lim, I. et al. (1994). Influence of breastfeeding and nipple stimulation on postpartum uterine activity. British Journal of Obstetrics and Gynaecology, 101, 804-805.

9. Kennedy, K. I., Labbok, M. H., \& Van Look, P. F. (1996). Lactational amenorrhea method for family planning. International Journal of Gynaecology and Obstetrics, 54, 55-57.

10. Dewey, K. G., Heinig, M. J., \& Nommsen, L. A. (1993). Maternal weight-loss patterns during prolonged lactation. American Journal of Clinical Nutrition, 58, 162-166.

11. Collaborative Group on Hormonal Factors in Breast Cancer (2002). Breast cancer and breastfeeding: collaborative reanalysis of individual data from 47 epidemiological studies in 30 countries, including 50302 women with breast cancer and 96973 women without the disease. Lancet, 360, 187-195.

12. Jernstrom, H., Lubinski, J., \& Lynch, H. T. et al. (2004). Breastfeeding and the risk of breast cancer in BRCA1 and BRCA2 mutation carriers. Journal of the National Cancer Institute, 96, 1094-1098.

13. Chiaffarino, F., Pelucchi, C., \& Negri, E. et al. (2005). Breastfeeding and the risk of epithelial ovarian cancer in an Italian population. Gynecologic Oncology, 98, 304-308.

14. Hopkinson, J. M., Butte, N. F., \& Ellis, K. et al. (2000). Lactation delays postpartum bone mineral accretion and temporarily alters its regional distribution in women. Journal of Nutrition, 130, 777-783.

15. Paton, L. M., Alexander, J. L., \& Nowson, C. A. et al. (2003). Pregnancy and lactation have no long-term deleterious effect on measures of bone mineral in healthy women: a twin study. American Journal of Clinical Nutrition, 77, 707-714.

16. Schmied, V., \& Barclay, L. (1999). Connection and pleasure, disruption and distress: women's experience of breastfeeding. Journal of Human Lactation, 15, 325-334. 
17. Schmied V., \& Lupton D. (2001). Blurring the boundaries: breastfeeding and maternal subjectivity. Sociology of Health and Illness, 23, 234-250.

18. Ware, J. E. Jr., \& Sherbourne, C. D. (1992). The MOS 36-item short-form health survey (SF-36). I. Conceptual framework and item selection. Medical Care, 30, 473-483.

19. Huang, I. C., Wu, A. W., \& Frangakis, C. (2006). Do the SF-36 and WHOQOL-BREF measure the same constructs? Evidence from the Taiwan population. Quality of Life Research, 15, 15-24.

20. Alonso, J., Ferrer, M., \& Gandek, B. et al. (2004). Health-related quality of life associated with chronic conditions in eight countries: Results from the International Quality of Life Assessment (IQOLA) Project. Quality of Life Research, 13, 283-298.

21. Hedov, G., Anneren, G., \& Wikblad, K. (2000). Self-perceived health in Swedish parents of children with Down's syndrome. Quality of Life Research, 9, 415-422.

22. Yamazaki, S., Sokejima, S., \& Mizoue, T. et al. (2005). Healthrelated quality of life of mothers of children with leukemia in Japan. Quality of Life Research, 14, 1079-1085.

23. Morrell, C.J., Spiby, H., \& Stewart, P. et al. (2000). Costs and effectiveness of community postnatal support workers: Randomised controlled trial. British Medical Journal, 321, 593-598.

24. Tseng, H., Lu, J., \& Tasi, Y. (2003). Assessment of health-related quality of life in Taiwan (I): development and psychometric testing of SF-36 Taiwan Version. Taiwan Journal of Public Health, 22, 501-511.

25. Tseng, H., Lu, J., \& Tasi, Y. (2003). Assessment of health-related quality of life in Taiwan ( $\Pi$ ): norming and validation of SF-36 Taiwan version. Taiwan Journal of Public Health, 22, 511-518.

26. Chuang, C. H., Hsieh, W. S., \& Guo, Y. L. et al. (2007). Chinese herbal medicines used in pregnancy: a population-based survey in Taiwan. Pharmacoepidemiology and Drug Safety, 16, 464-468.

27. Chuang, C. H., Chang, P. J., \& Hsieh, W. S., et al. (2007). A combined effect of employment status and trans-cultural marriage on breast feeding: A population-based survey in Taiwan. Paediatric and Perinantal Epidemiology, 21, 319-329.

28. World Health Organization. (2005). The World Health Report 2005-Make every mother and child count. Geneva, Switzerland: World Health Organization.

29. Bottorff, J. L. (1990). Persistence in breastfeeding: a phenomenological investigation. Journal of Advanced Nursing, 15, 201-209.

30. Kavanaugh, K., Meier, P., \& Zimmermann, B. et al. (1997). The rewards outweigh the efforts: breastfeeding outcomes for mothers of preterm infants. Journal of Human Lactation, 13, 15-21.

31. Mezzacappa, E. S., Guethlein, W., \& Vaz, N. et al. (2000). A preliminary study of breast-feeding and maternal symptomatology. Annals of Behavioral Medicine, 22, 71-79.

32. Mezzacappa, E. S., Guethlein, W., \& Katkin, E. S. (2002). Breast-feeding and maternal health in online mothers. Annals of Behavioral Medicine, 24, 299-309.

33. Groer, M. W. (2005). Differences between exclusive breastfeeders, formula-feeders, and controls: A study of stress, mood, and endocrine variables. Biological Research for Nursing, 7, 106-117.

34. Abou-Saleh, M. T., Ghubash, R., \& Karim, L. et al. (1998). Hormonal aspects of postpartum depression. Psychoneuroendocrinology, 23, 465-475.
35. Mozingo, J. N., Davis, M. W., \& Droppleman, P. G. et al. (2000). "It wasn't working." Women's experiences with short-term breastfeeding. American Journal of Maternal Child Nursing, 25, 120-126.

36. Harris, M., Nayda, R., \& Summers, A. (2003). Breasts and breastfeeding: Perspectives of women in the early months after birthing. Breastfeeding Review, 11, 21-29.

37. Mezzacappa, E. S., \& Katlin, E. S. (2002). Breast-feeding is associated with reduced perceived stress and negative mood in mothers. Health Psychology, 21, 187-193.

38. Galler, J. R., Harrison, R. H., \& Biggs, M. A. et al. (1999). Maternal moods predict breastfeeding in Barbados. Journal of Developmental and Behavioral Pediatrics, 20, 80-87.

39. Haider, R., Kabir, I., \& Hamadani, J. D. et al. (1997). Reasons for failure of breast-feeding counselling: mothers' perspectives in Bangladesh. Bulletin of the World Health Organisation, 75, 191-196.

40. Dulon, M., Kersting, M., \& Schach S. (2001). Duration of breastfeeding and associated factors in Western and Eastern Germany. Acta Paediatrica, 90, 931-935.

41. Bastiaansen, D., Koot, H. M., \& Ferdinand, R. F. (2005). Determinants of quality of life in children with psychiatric disorders. Quality of Life Research, 14, 1599-1612.

42. Goldbeck, L., \& Melches J. (2005). Quality of life in families of children with congenital heart disease. Quality of Life Research, 14, 1915-1924.

43. Heinig, M. J. (2002). Healthy mothers, healthy babies: Breastfeeding and beyond. Journal of Human Lactation, 18, 215-216.

44. Beck, C. T. (2001). Predictors of postpartum depression: An update. Nursing Research, 50, 275-285.

45. Dennis, C. L. (2004). Influence of depressive symptomatology on maternal health service utilization and general health. Archives of Women's Mental Health, 7, 183-191.

46. Da Costa, D., Dritsa, M., \& Rippen, N. et al. (2006). Healthrelated quality of life in postpartum depressed women. Archives of Women's Mental Health, 9, 95-102.

47. Flacking, R., Ewald, U., \& Nyqvist, K. H. et al. (2006). Trustful bonds: a key to "becoming a mother" and to reciprocal breastfeeding. Stories of mothers of very preterm infants at a neonatal unit. Social Science \& Medicine, 62, 70-80.

48. Isabella, P. H., \& Isabella, R. A. (1994). Correlates of successful breastfeeding: A study of social and personal factors. Journal of Human Lactation, 10, 257-264.

49. Galtry, J. (2003). The impact on breastfeeding of labour market policy and practice in Ireland, Sweden, and the USA. Social Science \& Medicine, 57, 167-177.

50. Fergerson, S. S., Jamieson, D. J., \& Lindsay, M. (2002). Diagnosing postpartum depression: Can we do better? American Journal of Obstetrics and Gynecology, 186, 899-902.

51. Ball H. L. (2003). Breastfeeding, bed-sharing, and infant sleep. Birth, 30, 181-188.

52. Ball, H. L., Ward-Platt, M. P., \& Heslop, E. et al. (2006). Randomised trial of infant sleep location on the postnatal ward. Archives of Disease in Childhood, 91, 1005-1010. 